\title{
Middle Class and Marginal? Socioeconomic Status, Stigma, and Self-Regulation at an Elite University
}

\author{
Sarah E. Johnson, Jennifer A. Richeson, and Eli J. Finkel \\ Northwestern University
}

\begin{abstract}
In four studies, the authors investigated the proposal that in the context of an elite university, individuals from relatively lower socioeconomic status (SES) backgrounds possess a stigmatized identity and, as such, experience (a) concerns regarding their academic fit and (b) self-regulatory depletion as a result of managing these concerns. Study 1, a correlational study, revealed the predicted associations between SES, concerns about academic fit, and self-regulatory strength. Results from Studies 2 and 3 suggested that self-presentation involving the academic domain is depleting for lower (but not higher) SES students: After a self-presentation task about academic achievement, lower SES students consumed more candy (Study 2) and exhibited poorer Stroop performance (Study 3) relative to their higher SES peers; in contrast, the groups did not differ after discussing a nonacademic topic (Study 3). Study 4 revealed the potential for eliminating the SES group difference in depletion via a social comparison manipulation. Taken together, these studies support the hypothesis that managing concerns about marginality can have deleterious consequences for self-regulatory resources.
\end{abstract}

Keywords: stigma, socioeconomic status, self-regulation, social identity threat

\begin{abstract}
It's hard to be the only black dancer. You feel separate, and you feel negated in a certain sense, and it's not that people are trying to make you feel bad, but it's just obviously around you.... . It's hard to be strong enough to be in that environment and to not feel wrong.

-Virginia Johnson, 2007
\end{abstract}

In the New York Times article, "Where Are All the Black Swans?" (Kourlas, 2007), Virginia Johnson, a retired ballet dancer, recalls the experience of being Black in the overwhelmingly White world of ballet. In the epigraph above, she articulates the subjective experience that can arise from the awareness of being different-feeling "separate" and "negated." In effect, she is describing the psychological experience at the intersection of underrepresen-

This article was published Online First January 31, 2011.

Sarah E. Johnson and Eli J. Finkel, Department of Psychology, Northwestern University; Jennifer A. Richeson, Department of Psychology and Institute for Policy Research, Northwestern University.

Sarah E. Johnson is currently the 2010-2011 American Psychological Association Executive Branch Science Fellow.

This research was conducted as part of Sarah E. Johnson's doctoral dissertation at Northwestern University under the direction of Jennifer A. Richeson and Eli J. Finkel. Portions of this work were presented at the 2008 Annual Meeting of the Society for Experimental Social Psychology and the 2009 Annual Meeting of the Association for Psychological Science. The research was supported by a Dissertation Research Award from the American Psychological Association to Sarah E. Johnson and a MacArthur Foundation Fellowship awarded to Jennifer A. Richeson.

We thank Katherine Phillips for her thoughtful input and comments on previous versions of this article. We are also grateful to Jessica Beltran, Jason Okonofua, Melissa Mitchell, Michelle Rheinschmidt, Deborah Son, and Sarah Stanton for help with data collection.

Correspondence concerning this article should be addressed to Sarah E. Johnson, Department of Psychology, Northwestern University, 2029 Sheridan Road, Evanston, IL 60208. E-mail: SarahEMJohnson@gmail.com tation and social stigma: Being different, with the implicit understanding that this difference renders one devalued, or "wrong" (Crocker, Major, \& Steele, 1998).

Now imagine another identity in a different context: A young woman from a relatively modest or even middle-class background, starting her first year of college at a prestigious (and expensive) private university. How will this student's socioeconomic background influence her experiences in this elite context? The acute awareness that her background is discrepant from her peers'-and, in turn, from the context at large-may lead her to wonder if she will measure up in other ways. For instance, given that academic achievement is central to the identity of the university, her marginalized status in this context may lead her to question her ability to meet its academic standards. In turn, managing these concerns may pose a psychological burden. The purpose of the current work is to examine this possibility. Specifically, the present research explores the psychological costs and consequences of being from a relatively lower socioeconomic status (SES) background in the context of an elite private university.

\section{Social Identity Threat}

In their seminal review, Crocker et al. (1998) situated stigma in the social psychological literature, defining it as a social identity that is devalued in a particular context (see also Major \& O'Brien, 2005). The key component of their definition is that stigma arises at the intersection between identity and context. Thus, as they note, stigma does not reside in the person "but in the unfortunate circumstance of possessing an attribute that, in a given social context, leads to devaluation" (Crocker et al., 1998, p. 506).

Social identity threat (Steele, Spencer, \& Aronson, 2002) - a broader perspective on stereotype threat (Steele \& Aronson, 1995) — provides a framework for understanding the circumstances under which a stigmatized social identity can become a psycho- 
logical liability. In their conceptualization of social identity threat, Steele and colleagues posit that cues from the environment, such as numerical underrepresentation, can signal to an individual that one of his or her social identities may be devalued in that environment (Murphy, Steele, \& Gross, 2007; Purdie-Vaughns, Steele, Davies, Ditlmann, \& Crosby, 2008; Steele \& Aronson, 1995; Steele et al., 2002). Perceiving such a cue, Steele and colleagues argue, forms a working hypothesis in the individual's mind-a theory of context - that triggers a search for additional information to confirm or disconfirm the suspected potential for social identity-based devaluation. Specifically, this theory of context instigates cognitive processes (e.g., vigilance) and affective responses (e.g., anxious arousal; Murphy et al., 2007) that undermine performance on tasks that are relevant in the context (e.g., Inzlicht \& Ben-Zeev, 2000, 2003; Sekaquaptewa \& Thompson, 2003). It is important to note that this framework is a theoretical extension of stereotype threat theory because it can account for identity-related processes beyond those associated with the threat of confirming a negative group performance stereotype. Nevertheless, little empirical research has tested the operation of these social identity threat effects in an identity that, albeit stigmatized in the context, is not associated with negative cultural stereotypes. The present work examines this possibility.

Walton and Cohen (2007) have proposed, furthermore, that social identity threat undermines individuals' sense of social acceptance, which can, in turn, result in impaired achievement in the domain (see also G. L. Cohen \& Garcia, 2008; Murphy \& Steele, 2009). Specifically, Walton and Cohen (2007) asserted that this belonging uncertainty "may take the form of a broad-based hypothesis that "people like me do not belong here"” (p. 83) and will not succeed, which, not surprisingly, undermines individuals' investment in the tasks most central to the environment (e.g., academic achievement in the university context). Thus, like Steele et al.'s (2002) notion of theory of context, Walton and Cohen proposed a process whereby, having formed a hypothesis regarding their belonging, individuals will be vigilant for and responsive to cues that might be diagnostic of their fit, or lack thereof, in the domain.

In the current article, we build on this research to propose that social identity threat, by virtue of undermining individuals' fundamental sense of belonging — or legitimacy_in a given context, may manifest as concerns about competency in domains most central to that context. In an academic context, for instance, possessing a marginal, stigmatized identity may manifest as concerns about one's academic competency. The present article examines whether, in an elite college environment, individuals' SES background predicts the extent to which they harbor concerns about academic competency and, furthermore, whether contending with such academic competency concerns, like managing other forms of identity threat (Inzlicht \& Kang, 2010; Inzlicht, McKay, $\&$ Aronson, 2006), is experienced as ego depleting.

\section{SES Stigma}

The social identity threat literature provides the groundwork for understanding the causes, and especially the consequences, of experiencing the threat that one's identity might be devalued in a particular context (Steele et al., 2002). However, much of the extant research in the achievement domain in this tradition has primarily focused on the social identities of race (i.e., Black students and academic pursuits in general) and gender (i.e., women and achievement in math and natural science), both of which are visible characteristics. Do these same processes apply to SES, which is largely invisible? A few researchers have extended social identity threat research to the identity of SES. In particular, Croizet and Claire (1998) found performance decrements among lower SES French students under a situation of identity threat. More recently, this effect was demonstrated in a sample of college students in the United States (Spencer \& Castano, 2007).

In addition to this work on academic performance, SES has been found to influence social and emotional well-being in the context of higher education (Ostrove \& Long, 2007). For instance, in a retrospective study, Ostrove (2003) found that women from lower and middle-class backgrounds reported feeling more alienated or belonging less during their time spent at an elite college-echoing Walton and Cohen's (2007) work on the effects of racial underrepresentation at elite private universities. Moreover, students from lower SES backgrounds have also been found to experience concerns about their academic fit and competency in the elite university environment (Granfield, 1991). In his ethnographic study of working-class students at an Ivy League law school, Granfield (1991) observed that these students, "although initially proud of their accomplishments ... soon came to define themselves as different and their backgrounds a burden ... [They] began to experience a crisis in competency" (p. 336). The current work seeks to bring empirical evidence to bear on this experience by examining the extent to which SES predicts concerns about academic competency.

If indeed the identity of a relatively lower SES background in the context of a high-status university setting is associated with academic concerns, as observed by Granfield (1991), what might be the consequences? One possibility, as Granfield suggested, is that managing these identity-based concerns is a burden-exacting a toll on individuals' psychological resources. This hypothesis is consistent with Inzlicht et al.'s (2006) "stigma as ego depletion" hypothesis - that is, that stigma itself serves as a drain on individuals' self-regulatory resources. On the basis of the strength model of self-regulation (Baumeister, Vohs, \& Tice, 2007; Muraven \& Baumeister, 2000), which proposes that the currency of selfregulation is a limited but renewable resource, Inzlicht et al. (2006; Inzlicht \& Kang, 2010) reasoned that when resources are usurped by coping with stigma, individuals will experience ego depletion. Consistent with this proposal, Inzlicht and colleagues (Inzlicht \& Kang, 2010; Inzlicht et al., 2006) have demonstrated evidence of "stereotype threat spillover" in which coping with stereotype threat impairs performance on tasks requiring self-regulation, even those occurring outside the stereotype threat situation (Inzlicht \& Kang, 2010; see also Beilock, Rydell, \& McConnell, 2007). For instance, individuals performed worse on a task requiring self-regulation (e.g., consumed more ice cream) when in a situation of stereotype threat (women in a math context) compared to a nonthreat situation (Inzlicht \& Kang, 2010)

Although this idea is compelling and certainly consonant with Granfield's (1991) ethnographic work, it is not obvious that the work of Inzlicht and colleagues (Inzlicht \& Kang, 2010; Inzlicht et al., 2006; see also Beilock, Rydell, \& McConnell, 2007) generalizes to the identity of SES. First, as mentioned previously, SES is a largely invisible characteristic, unlike race and gender, and 
therefore it is not obvious whether individuals notice or are able to track it sufficiently in the context in order to experience stigma by virtue of their relatively lower SES. Second, SES backgrounds that are discrepant (i.e., underrepresented) in the context of an elite private university are not necessarily those stigmatized in broader society. That is, even SES backgrounds falling within the U.S. middle class are remarkably underrepresented at the country's most elite private universities. Indeed, this is one reason many of these universities have recently adopted financial aid strategies such as waiving tuition and loans for families with household incomes of up to $\$ 60,000$ and heavily subsidizing costs even for those with household incomes of up to $\$ 180,000$ (Rimer \& Finder, 2007). Hence, many individuals who are of relatively lower SES at an elite university are squarely within the U.S. middle class and therefore have not been subjected to cultural stereotypes linking their SES to poor academic achievement, as have poor individuals and Black and Latino students (and women in the math and science domains). Thus, it remains unclear whether SES, particularly relatively lower SES rather than objectively low SES (i.e., poverty), will be experienced as a stigma in the context of an elite private university and result in the aforementioned concerns about academic competence that, in turn, spill over in the form of ego depletion. As such, the present work both broadens and extends Inzlicht and colleagues' (2006, 2010) work on stereotype threat spillover through an examination of the psychological burden of managing an identity that, while stigmatized in the context, is not negatively stereotyped culturally.

\section{Overview of Studies}

The premise of the present research is that managing concerns regarding academic achievement is effortful and thereby depletes self-regulatory resources (Inzlicht et al., 2010, 2006). If students from lower SES backgrounds are differentially burdened with concerns about academic achievement compared to their higher SES counterparts, as predicted by Granfield (1991), then engaging in self-presentation regarding academic achievement should be relatively more effortful and thus more depleting for them. We test this hypothesis in the current work. First, Study 1 uses survey procedures to establish the hypothesized relation between the constructs of interest: SES, academic concerns in an elite context, and self-regulation. Next, a series of experiments further explores the relation between academic concerns and self-regulatory strength. Studies 2 and 3 test the hypothesis that, compared to relatively higher SES students, lower SES students will be more depleted after talking about an academic-relevant topic. Last, Study 4 examines the potential to eliminate the SES group difference in depletion by using a social comparison manipulation to increase or decrease individuals' academic competency concerns and thus the perceived demands of the self-presentation task. Taken together, the present work examines the extent to which, in the context of an elite university, a lower SES background is experienced as a stigmatized identity-one that engenders concerns about academic competency that, in turn, deplete selfregulatory resources.

\section{Study 1}

Before turning to the primary question of the present worknamely, that managing the concerns associated with a lower SES background can be depleting - we first address the assumptions regarding the experience of a lower SES background on an elite college campus. More specifically, in this first study we sought to substantiate the process suggested by Granfield's (1991) ethnographic work: that lower SES serves as a potential source of social identity threat by undermining individuals' domain-relevant confidence (i.e., the "crisis in competency" hypothesis). Thus, the first goal of Study 1 was to test the hypothesis that at an elite university, SES is negatively associated with concerns regarding the domain of academics. The second goal was to provide an initial test of the hypothesis that managing the lower SES background in an elite college environment depletes self-regulatory resources.

In Study 1, we administered a survey to a sample of Northwestern University undergraduates to address the contentions that (a) students from relatively lower SES backgrounds at an elite institution are sensitive to discrepancies between their own background and that of their fellow students; (b) sensitivity to the discrepancy in SES is associated with concerns about academic competence; and finally, (c) sensitivity to this SES identity discrepancy is associated with lower self-regulatory strength.

\section{Method}

Participants. Four hundred and seventy-four (264 female, 18 who did not report gender information) Northwestern undergraduates completed the survey in partial fulfillment of a requirement for an introductory psychology course. Of these, $61 \%$ were White, 18\% were Asian American, 6\% were Latino, 5\% were biracial/ multiracial, $5 \%$ were Black, and the remaining $5 \%$ did not report race/ethnicity.

\section{Measures.}

Socioeconomic status (SES). In the current set of studies, we used family household income to assess SES. ${ }^{1}$ Participants selected the income range appropriate for their family from a set of five options, based on categories used in the U.S. Census: (a) less than $\$ 25,000$; (b) $\$ 25,001-\$ 40,000$; (c) $\$ 40,001-\$ 70,000$; (d) $\$ 70,001-\$ 90,000$; and (e) $\$ 90,001$ or more.

Sensitivity to SES-based identity discrepancy (SSID). We created a six-item scale to assess individuals' subjective experience of their SES relative to their peers (i.e., their experience of stigma). This scale comprised items assessing perceptions of the relative privilege of one's peers at Northwestern (e.g., "Most students at Northwestern come from a more privileged background than I do") and perceptions of one's discrepancy from that norm (e.g., "My family background/upbringing is similar to that of the typical Northwestern student," reverse-scored). Participants rated their agreement with each statement using a scale ranging from 1 (strongly disagree) to 7 (strongly agree). Together, these six items showed good reliability $(\alpha=.85)$.

Academic concerns. We measured concerns about measuring up to the institution's academic standards (i.e., academic competency) with one face-valid item assessing perceptions of academic fit ("To what extent do you fit in academically at Northwestern?").

\footnotetext{
${ }^{1}$ Although household income is a relatively crude measure of SES, compared with measures involving multiple indicators (e.g., education and occupation), it has nevertheless been shown to predict important outcomes (for a review, see Krieger, Williams, \& Moss, 1997).
} 
Participants responded to this question using a scale ranging from 1 (not at all) to 7 (completely).

Self-regulation. As in Inzlicht et al. (2006), self-regulation was measured with the Self-Efficacy for Self-Regulated Learning scale (SESRL; Gredler \& Garavalia, 2000). This is an 11-item scale that contains items assessing individuals' experiences with successful self-regulation in the domain of academics (e.g., "How well can you plan your class work?"; "How well can you set and honor your priorities?"). Participants responded to these items using a scale ranging from 0 (not well/not at all) to 100 (very well/very often).

Procedure. Participants completed the survey in a masstesting session that took place during a class period at the beginning of the academic term. The SES measure was included in a set of demographic questions that appeared on the first page of the packet. The remaining measures were embedded in a host of unrelated questionnaires.

\section{Results and Discussion}

Fifteen percent of the sample did not complete the SES measure. Among those who completed it, the modal response was the highest income range ( $\$ 90,000$ or more): $56 \%$ selected $\$ 90,000$ or more; $10 \%$ selected $\$ 70,001-\$ 90,000 ; 12 \%$ selected $\$ 40,000-$ $\$ 70,000 ; 3 \%$ selected $\$ 25,001-\$ 40,001$; and $4 \%$ selected $\$ 25,000$ or less. As noted previously, the study participants who are relatively lower in SES (i.e., the minority reporting incomes under $\$ 90,000)$ are, in fact, primarily from within the North American middle class.

SES and stigma sensitivity. To test our first question regarding the association between SES and the experience of stigma, we examined the relation between SES and SSID, the measure of sensitivity to SES-based identity discrepancy. As expected, these constructs were negatively related $(r=-.33, p<.001)$. That is, individuals' sensitivity to the relative privilege of their peers increased as their reported household income declined. More simply, individuals from relatively lower SES backgrounds are both aware of and sensitive to the fact that they differ from their peers along this dimension. Next, we tested Granfield's (1991) crisis in competency hypothesis that SES is associated with academic competency concerns. As expected, the association between SES and academic fit was positive and significant $(r=.11, p=.029)$, albeit small. In other words, as individuals' family income declines, so too do their perceptions of fitting in academically at the university.

Of course, individuals might experience stigma sensitivity and question their academic competency on the basis of a perceived identity discrepancy along a dimension other than SES. For instance, Black and Latino incoming first-year students at elite private universities have been shown to experience greater concern about potential stigma on campus and greater academic competency concerns than their White counterparts, even prior to their arrival on campus (e.g., Massey, Charles, Lundy, \& Fischer, 2003). Given the correlation between race and SES in the United States, it is possible that our results could be due to racial differences in either stigma sensitivity or academic competency concerns. Supplementary analyses controlling for participant race, however, revealed that the relation between SES and stigma sensitivity $(r=-.32, p<.001)$ and the relation between SES and academic fit $(r=.11, p=.026)$ remain virtually unchanged.

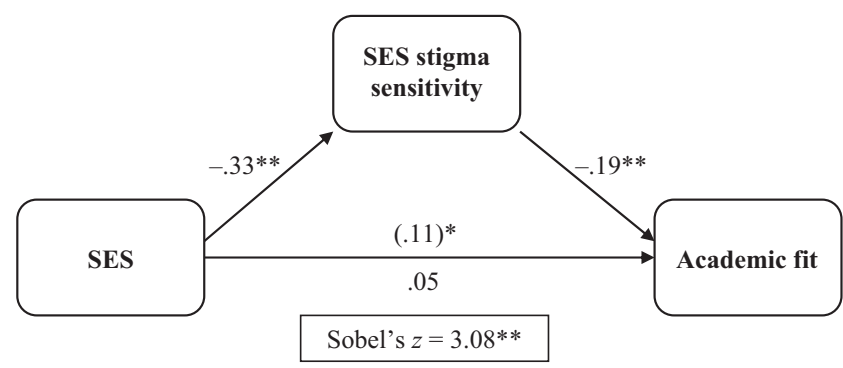

Figure 1. Study 1: Examining whether stigma sensitivity based on socioeconomic status (SES) mediates the association of SES and academic fit. The values in the figure represent standardized regression coefficients. The coefficient in parentheses represents the association of SES with academic fit without SES stigma sensitivity. ${ }^{*} p<.05 .{ }^{* *} p<.001$.

Finally, we have proposed that a psychological threat process may be relevant here, such that it is not individuals' SES per se that undermines their sense of academic competence but rather their awareness of and sensitivity to their lack of fit because of their SES - that is, their subjective experience of SES-based stigma. To address this proposed process, we conducted a mediational analysis employing the sequence of steps suggested by Baron and Kenny (1986). These results are presented in Figure 1. Step one revealed that, as reported previously, SES significantly predicted academic fit, $\beta=-.11, t(392)=2.15, p=.032$. Step two revealed that SES also significantly predicted the proposed mediator, SSID, $\beta=-.33, t(399)=6.87, p<.001 .^{2}$ Step three revealed that SSID significantly predicted academic fit, $\beta=-.19, t(393)=3.65, p<$ .001 , and that when SSID was included in the model, the effect of SES on academic fit was no longer significant, $\beta=.05$, $t(393)=$ $0.91, p=.37$. Finally, a Sobel test confirmed that SSID significantly mediated the relationship between SES and academic fit $(Z=3.08, p<.001)$.

SES and self-regulation. The second goal of this study was to test the hypothesized link between managing these identity concerns and self-regulation. If a lower SES identity is experienced as a stigmatized identity in the context of an elite university then, on the basis of Inzlicht et al. (2006), we might expect to find an association between a construct related to the experience of this stigma and reports of self-regulatory success. Thus, we propose that the measure of SES stigma sensitivity (SSID) - to the extent that it predicts the subsequent management of stigma-should predict self-regulatory depletion. As predicted, SES stigma sensitivity (SSID) was negatively correlated with self-reported selfregulatory success (SESRL; $r=-.13, p=.005$ ). This association remains reliable after controlling for race $(r=-.12, p=.014)$.

In sum, the results of Study 1 suggest that a lower SES background at an elite university may be associated with harboring academic concerns. In particular, the present results substantiate the notion that individuals' confidence about their academic fit at Northwestern may be shaped, at least in part, by their SES background. Furthermore, consistent with the social stigma literature, the subjective experience that one's identity deviates from what is

\footnotetext{
${ }^{2}$ In this and the remaining studies reported herein, differences in degrees of freedom reflect missing data on some measures.
} 
normative in the environment statistically mediates the association between SES and perceived academic competency. In other words, it is the psychological experience arising from the awareness of one's deviation from the majority (in terms of SES), rather than SES per se, that undermines perceptions of academic competence.

Finally, these survey results also provide preliminary support for the consequences of being from a lower SES background at an elite university for self-regulatory success: SES stigma sensitivity was negatively associated with reports of successful selfregulation. Although this finding was in the predicted direction, the association was quite small. Following the logic of Inzlicht et al. (2006), we reason that it is the burden arising from this identity-namely, the concerns that must be managed-that requires and thus depletes these resources. If this is indeed the case, we would expect situations that engage the stigmatized identity directly-and/or specific concerns that arise from that identitywould be most likely to deplete individuals' self-regulatory resources. Indeed, in the present sample there was no direct relationship between SES and self-regulatory strength (SESRL; $r=$ $.03, p>.50$ ), supporting the idea that rather than being a consequence of SES background per se, self-regulatory depletion arises from contending with the concerns trigged by the identity in threatening contexts and situations. To examine this proposed process further, the remaining studies made use of a selfpresentation paradigm in which individuals discuss topics that are likely to activate lower SES students' academic competency concerns to ascertain their role in engendering self-regulatory depletion.

\section{Study 2}

The goal of Study 2 was to examine the hypothesis that contending with academic competency concerns undermines the selfregulatory resources of lower SES students at elite private universities. To test this idea, we recruited students with either higher or lower SES backgrounds (on the basis of family household income) and asked them to discuss an achievement-relevant topic. In particular, participants were asked to talk about a recent academic success, based on the logic that harboring concerns about the domain of achievement might make this topic relatively taxing to discuss. To explore the consequences of self-presentation involving the achievement domain, we adopted the interaction paradigm used by Richeson and Trawalter (2005). Specifically, the interaction took place in the context of a videotaped interview situation where the experimenter interviewed the participant from behind a video camera. This paradigm is particularly appropriate for the present research, as the situation it creates-talking to a fellow undergraduate about academics - is likely one these participants encounter often in their daily lives.

Adopting the standard two-task paradigm used by ego-depletion researchers (e.g., Baumeister et al., 2007; Muraven, Tice, \& Baumeister, 1998), the discussion task (Task 1) was followed by a subsequent, albeit ostensibly unrelated, task intended to measure self-regulatory depletion (Task 2). The measure of depletion in this study was consumption of unhealthy foods-in this case, candy. Consumption of unhealthy snacks has been used in prior research as a measure of ego depletion based on the rationale that effective self-regulation entails resisting the urge to eat appealing and tasty but unhealthy and nonnutritive snacks (see Baumeister, DeWall,
Ciarocco, \& Twenge, 2005; Inzlicht \& Kang, 2010). Thus, participants with fewer self-regulatory resources remaining after the discussion task should be less able to restrain the impulse to eat candy and so will consume more. The hypothesis for Study 2, then, is that individuals from a lower SES background will be more depleted by discussing academic achievement with a peer compared with their higher SES peers and thus will subsequently consume more grams of candy.

\section{Method}

Participants. Fifty-one (31 female) Northwestern University undergraduates participated in this study in exchange for partial fulfillment of a course requirement. Of these, $57 \%$ were White, $20 \%$ were Asian, $19 \%$ were Latino, and $4 \%$ were biracial/ multiracial. Twenty-seven lower SES and 24 higher SES participants were selected on the basis of their reports of household income, using the measure reported in Study 1, provided at a mass-testing session held at the beginning of the term. ${ }^{3}$ The highest category on the measure ( $\$ 90,000$ or more) served as the cutoff for categorizing individuals as lower or higher SES. Recall that the $\$ 90,000$ or more category was the modal response in Study 1. By dichotomizing SES on the basis of this cutoff, individuals falling below this income level constituted a numerical minority group (i.e., those with backgrounds that differed from the norm) and thus were the individuals who might be susceptible to experiencing stigma by virtue of their relatively lower SES. On the basis of a second, open-ended measure of family household income completed at the end of the experimental session, participants categorized as lower SES at prescreening indeed reported substantially lower household incomes $(M=\$ 53,848)$ than participants categorized as higher SES $(M=\$ 210,238), t(42)=3.72$, $p=.001, r=.50$.

Procedure. When participants arrived for their individual experimental sessions, they were greeted by a same-sex experimenter and led to a room where they were seated at a desk. Next, the experimenter explained that the session would be composed of several different short studies. After obtaining consent, the experimenter introduced the first task, the self-presentation task. In particular, the experimenter explained that the lab was collaborating with researchers from another university who were interested in understanding the experiences of college students. To this end, these researchers were collecting short videos of undergraduates talking about some aspect of their lives. The participant was then led to another room and seated on a couch, facing a video camera ( $\sim 8 \mathrm{ft}[2.4384 \mathrm{~m}]$ away).

The experimenter explained that the participant had already been assigned to a discussion topic and handed him/her a list of participant identification numbers and topics, asking the participant to find his or her identification number and topic on the list. (The list was rigged so that the numbers of all the participants in the study were assigned the topic "academic success.") The discussion task began when the experimenter started the camera and initiated the discussion, reading from the topic prompt: "You have

\footnotetext{
${ }^{3}$ Of the 27 lower SES participants, 18 were White, five were Latino, three were Asian, and one identified as biracial/multiracial. Of the 24 higher SES participants, 11 were White, five were Latino, seven were Asian, and one identified as biracial/multiracial.
} 
been assigned to talk about a recent academic success. Please start by describing what it was." When the participant finished talking, the experimenter moved on to the next prompt to elicit further discussion (e.g., "Please talk about how you felt about this event: Do you remember what you were feeling at the time?"; "Describe what made this success so rewarding: Why was this success important to you?"). The experimenter continued giving prompts until the participant had been talking for approximately $5 \mathrm{~min}$.

After $5 \mathrm{~min}$, the experimenter explained that the discussion task was now complete and returned participants to the first experimental room. At this point, the experimenter administered the dependent measure of candy consumption under the guise of a taste preference study (Baumeister et al., 2005). The experimenter informed the participant that he or she had been assigned to the familiar foods condition and would be rating two familiar foods: Food A (Twizzler bites) and food B (M\&M candies). The experimenter placed a bowl of each type of candy on the desk before the participant and handed him/her a rating sheet to evaluate each candy on 12 dimensions. The participant was told, "Please be sure to sample at least a few before making your ratings." The experimenter then left the participant alone in the room to complete the task.

After approximately $3 \mathrm{~min}$, the experimenter returned, removed the candy, and handed the participant a set of final questionnaires, which included the household income item. At the end of the session, the participant was debriefed, thanked, and dismissed. At this point, the experimenter weighed each container of candy.

\section{Results and Discussion}

Prior to analyses, data from five participants were eliminated: Three participants did not consent to be videotaped, one participant reported that he or she had fasted prior to the session, and one participant's session was compromised by an experimenter error. Thus, data from the remaining 46 participants constituted the final sample. Candy consumption was determined by subtracting the postsession weight of each candy container from the starting weight; the number of grams consumed was averaged across the two candy types. These scores were submitted to a one-way analysis of covariance, with sex of participant as a covariate (men, on average, consumed more grams of candy than did women). Consistent with predictions, this analysis revealed a significant main effect of participant SES, $F(1,43)=4.31, p=.044, r=$ $.30{ }^{4}$ As expected, participants from lower SES backgrounds consumed more grams of candy $(M=13.06, S D=7.79)$ after discussing a recent academic success compared with their higher SES peers $(M=9.36, S D=5.85)$. These results provide support for the hypothesis that talking about a recent academic success is more depleting (resulting in greater candy consumption) for students from lower, compared with higher, SES backgrounds. In other words, the present results are consistent with our primary hypothesis that relative to students from higher SES backgrounds in this academically oriented context, students from lower SES backgrounds are susceptible to cognitive depletion after engaging in a self-presentation task that involves the domain of academic achievement-a domain that triggers lower SES individuals' academic competency concerns.

Although the present results are consistent with our central hypothesis, there remain a number of plausible alternative expla- nations for the findings. One possibility is that the results reflect stable SES group differences in self-regulatory capacity. That is, rather than stemming from differences in the experience of the self-presentation task, as we have argued, the depletion results could instead have arisen from inherent group differences in selfregulatory ability. Indeed, recent research suggests that SES can impact individuals' executive functioning (e.g., Evans \& Schamberg, 2009; Noble, Norman, \& Farah, 2005). Although it is certainly possible that such differences contributed to the effects found in Study 2, we believe that it is unlikely that they completely account for the results. Specifically, research regarding the association between SES and executive function has largely examined the detrimental consequences of living at or below the poverty line (e.g., Evans \& Schamberg, 2009; Farah et al., 2006). Recall that in the present research, the group designated as lower SES consisted mostly of students from backgrounds that are more accurately characterized as middle class rather than poor. Furthermore, all participants exhibited evidence of cognitive functioning that was sufficiently high to gain admission to an elite private university. Nevertheless, a stronger test of our hypothesis requires evidence that it is not self-regulation in general that is more depleting for lower, compared with higher, SES individuals but rather selfregulatory situations that involve the academic domain. The purpose of Study 3 was to address this question. Specifically, Study 3 tested whether self-presentation that is relevant to academic achievement, but not self-presentation that is not relevant to academic achievement, engenders the SES group difference in ego depletion.

\section{Study 3}

The goal of Study 3 was to replicate and extend the findings of Study 2 to determine if the SES group difference in depletion was indeed due to engaging in self-presentation regarding academic achievement or rather from chronic SES differences in executive ability. Specifically, in Study 3 we sought to demonstrate that the SES difference in depletion that emerged in Study 2 arose because lower (but not higher) SES participants had to manage identityrelated concerns regarding the domain of academic achievement (i.e., competency concerns). To test this idea, students from higher and lower SES backgrounds were again asked to engage in a self-presentation task. Rather than discussing only a topic that was relevant to the domain of academic achievement (i.e., a stigmarelevant topic) as in Study 2, this time half of the participants discussed a topic that was not related to academic achievementnamely, geographic preferences (i.e., a stigma-irrelevant topic). Instead of being interviewed and videotaped by the experimenter in the self-presentation task, participants in this study made an audio recording on their own.

This study also employed a different dependent measure from Study 2, enabling us to examine whether the SES group difference in depletion generalizes to depletion measures beyond candy consumption. Specifically, after the self-presentation task, participants completed the Stroop (1935) color-naming task, a measure of

\footnotetext{
${ }^{4}$ The effect of SES on candy consumption remains significant when race is included in the model, $F(1,42)=4.22, p=.046$. Race does not significantly predict candy consumption $(p>.14)$.
} 
inhibitory control used widely in previous research to assess ego depletion (e.g., DeWall, Baumeister, \& Vohs, 2008; Inzlicht et al., 2006; Richeson \& Trawalter, 2005). We predicted that the influence of participant SES background on Stroop task performance would vary by discussion topic. In replication of Study 2, lower SES participants in the academic achievement self-presentation condition were expected to be more depleted than higher SES participants in this condition. By contrast, we expected to find no SES group difference in depletion among participants in the stigma-irrelevant self-presentation condition. In other words, we predicted that individuals from lower SES backgrounds in the stigma-relevant self-presentation condition would perform worse on the Stroop task (i.e., evidence greater ego depletion) than participants in any of the other three conditions (i.e., lower SES participants in the stigma-irrelevant self-presentation condition and higher SES participants in either self-presentation condition).

\section{Method}

Participants and design. Seventy-nine (48 female) White Northwestern undergraduates participated in this study in partial fulfillment of a course requirement. Forty lower and 39 higher SES participants were selected on the basis of demographic information provided at a mass-testing session held at the beginning of the term. As in Study 2, participants were categorized as lower or higher SES on the basis of their reports of household income, with those reporting incomes below $\$ 90,000$ categorized as lower and those above categorized as higher. At the end of the experimental session, participants again reported their family income on an open-ended item. Lower SES participants reported family incomes that were on average significantly lower $(M=\$ 70,129)$ than higher SES participants $(M=\$ 229,143), t(68)=2.80, p=.007$, $r=.32$. The design was a 2 (participant SES background: lower vs. higher) $\times 2$ (discussion topic: stigma-relevant vs. stigmairrelevant) between-subjects factorial.

Stroop task. The Stroop task was used to assess selfregulatory depletion. In this task, participants were asked to identify the script color of a word presented on the screen as quickly as possible, using one of four different color-coded computer keys (red, blue, green, and yellow). There were three types of trials: compatible trials, in which the script color matched the color-word presented (e.g., the word BLUE in blue print); incompatible trials, in which the script color differed from the color-word presented (e.g., the word BLUE in red print); and control trials, in which a row of $x \mathrm{~s}(x x x x)$ was printed in one of the four colors used in the task. To respond correctly on the incompatible trials (i.e., indicating the color of the script, not the word's meaning), individuals must inhibit the prepotent response of reading the word. After a series of practice trials, participants completed two blocks of 12 experimental trials. The presentation of each stimulus trial was preceded by a fixation cross, which appeared on the screen for 100 ms. Target stimuli appeared on the screen until participants made a response. Both responses and latencies were recorded.

Because response inhibition draws upon cognitive resources that are similar to those used by other forms of self-regulation, the Stroop task can be used as a measure of depletion. If individuals have fewer resources available after engaging in effortful selfpresentation - that is, if they are experiencing depletion-they will have a more difficult time performing the Stroop task. Specifically, self-regulatory depletion is indicated by Stroop interference or the difference in response latencies to incompatible compared to control trials; greater Stroop interference indicates greater cognitive depletion.

Procedure. When participants arrived for their individual sessions, they were greeted by a female experimenter and seated at a table in the experimental room. After obtaining consent, the experimenter introduced the first study, the self-presentation task. This task was framed as part of a large national project, whose coordinators had sent an audiotaped introduction to explain the goal of the project and the task the participant would be completing. The use of audiotaped instructions served two purposes: First, it bolstered the cover story. Second, it enabled the experimenter to remain blind to condition (i.e., discussion topic assignment). The experimenter seated the participant in front of a computer, provided him or her with headphones, and started the audiotaped introduction to the study; the experimenter then left the room while the participant listened to the recording.

The introduction began with an elaboration of the cover story. The narrator said that this national project was investigating how individuals' future outcomes are influenced by the type of college or university they attend. To do this, the researchers were collecting audiotapes made by students from different schools around the country "talking about a variety of different topics related to their college experience." To underscore the academic domainrelevance of the task, the explanation emphasized the researchers' interest in "the relationship between the type of college one attends and future outcomes."

Next, participants heard a description of the discussion topic to which they were assigned. Rather than discussing a recent academic success, as in Study 2, participants in this study assigned to the stigma-relevant topic were asked to discuss their "expectations for their future outcomes, and how attending Northwestern would influence these outcomes." To ensure this topic was construed as relevant to academic achievement, the cover story reinforced the connection between undergraduate academic experience and future achievements. For instance, participants in the stigma-relevant condition were told:

This research is especially important because a survey conducted by U.S. News and World Report indicates that which college you go to now has more influence on your life outcomes after graduation. In particular, this survey found that graduates of top schools like Northwestern tend to do well after graduation.

In contrast, participants in the stigma-irrelevant condition heard the above description, except the words "do well after graduation" were replaced with a reference to future geographic location: that graduates of Northwestern "tend to have a lot of options in terms of where they live." They were then told they had been assigned to discuss "which region of the country you would like to live in, in the future" and how attending Northwestern would influence these geographic preferences. This topic was used because it was similar to the stigma-relevant condition in that it pertained to the future and the influence of Northwestern on that future but did not involve the domain of achievement. Finally, all participants were told that upon completion of the study, their tape would be sent to the project headquarters to be evaluated by a team of trained research assistants. 
At the conclusion of the audiotaped instructions, the experimenter returned to initiate the discussion task: She handed the participant an envelope containing a reminder of his or her discussion topic assignment, started the audio-recording device, and left the participant in the room for 4 min to complete the discussion task. After $4 \mathrm{~min}$, the experimenter returned, removed the recording device and discussion topic assignment materials, and explained that this part of the study was now complete. Next, participants completed the Stroop task. Last, participants completed a final questionnaire that included the open-ended measure of household income. At the end of the session, participants were debriefed about the purpose of the study, thanked, and dismissed.

\section{Results and Discussion}

Prior to analyses, data from five participants were excluded: Two participants failed to complete the discussion task, and for three participants, Stroop interference scores could not be computed due to a high number of errors. Thus, data from the remaining 74 participants constituted the final sample. Response latencies from the Stroop task were trimmed and transformed on the basis of procedures used in previous work (Richeson \& Shelton, 2003; Richeson \& Trawalter, 2005). In particular, reaction times exceeding $2.5 \mathrm{SDs}(\sim 1,300 \mathrm{~ms})$ were recoded as $1,300 \mathrm{~ms}$, and reaction times less than $200 \mathrm{~ms}$ were recoded as $200 \mathrm{~ms}$. These scores were then log-transformed to correct for the positive skew typical of response latencies. For ease of interpretation, however, values presented in the main text and figures are untransformed. Finally, Stroop interference scores were calculated by subtracting participants' mean score for control trials from their mean score for incompatible trials. Stroop interference scores ranged from -154 $\mathrm{ms}$ to $340 \mathrm{~ms}(M=89 \mathrm{~ms}, S D=97 \mathrm{~ms})$.

Recall that our primary prediction was that lower SES participants would be uniquely impacted by the achievement-related discussion topic and, as a result, would exhibit greater depletion than participants in the other three conditions. Prior to testing this specific a priori hypothesis, however, participants' Stroop interference scores were submitted to a two-way analysis of variance, with participant SES group and discussion topic condition as between-subjects factors. Results revealed no significant main effects or interaction effects ( $p$ s $>.12$ ). Importantly, the planned one- versus three-group contrast ${ }^{5}$ testing our a priori hypothesis was significant, $t(70)=2.06, p=.04, r=.24$ (see Figure 2); lower SES participants who discussed the achievement-related topic exhibited significantly greater Stroop interference compared with participants in the remaining three conditions. Further examination of the means within each experimental condition revealed that, consistent with Study 2, in the stigma-relevant topic (i.e., future outcomes) condition, lower SES participants performed marginally worse than their higher SES peers, $t(35)=1.75, p=$ .089. It is important to note that the Stroop performance of higher and lower SES participants did not differ after participants discussed the stigma-irrelevant topic, $t(35)=0.55, p=.58$.

The results of Study 3, therefore, provide support for the contention that stigmatized identity management is depleting. Specifically, Study 3 revealed that lower SES participants asked to engage in self-presentation involving a stigma-relevant topic (future outcomes) were more depleted compared with lower SES participants asked to discuss a stigma-irrelevant topic (geographic preferences) and higher SES participants asked to discuss either type of topic. In other words, participants for whom the selfpresentation task required managing identity-relevant concerns performed worse on the Stroop task compared with all other participants. Second, this study employed a different dependent measure, suggesting the depletion effects of Study 2 generalize beyond the candy consumption paradigm, consistent with Baumeister et al.'s (2007) strength model of self-regulation.

We have argued that the SES group difference in depletion resulting from these self-presentation experiences arises from the fact that one group (the lower SES participants), but not the other (higher SES participants), is burdened by the demands of managing concerns that are evoked by feeling stigmatized in the context (i.e., academic competency concerns). If this is indeed the case, then it stands to reason that the SES group difference in depletion would be eliminated if the discrepancy in task demands between higher and lower SES individuals were eliminated. Thus, the final study, Study 4, seeks to level the proverbial playing field by manipulating lower and higher SES students' academic competency concerns.

\section{Study 4}

The goal of Study 4 was to equate the task demands of the self-presentation task to discern whether higher and lower SES participants would evidence comparable levels of self-regulatory depletion afterwards. In this study, we build on the paradigm introduced in Study 3 in which participants were asked to create an audiotape that would ostensibly be evaluated by an outside audience. To manipulate task demands, Study 4 included two additional conditions in which the audience provided a basis for upward or downward social comparison. Previous research suggests that situations of upward and downward social comparison differ in terms of the demands they impose. Specifically, Mendes, Blascovich, Major, and Seery (2001) found that individuals making an upward social comparison showed patterns of physiological reactivity that reflect the psychological state of threat (i.e., when individuals perceive the demands of a stressor to exceed their resources to cope with those demands). In contrast, individuals making a downward social comparison showed physiological responses consistent with a challenged state (i.e., when individuals perceive they have sufficient resources to cope). This evidence suggests that one can manipulate task demands via social comparison; an upward comparison should increase demands and a downward comparison should attenuate task demands.

Because participants were discussing the influence of Northwestern on their future outcomes - an academic achievementrelated topic (see Study 3) - we manipulated demands by introducing a comparison to the outcomes of students at schools construed as either more or less prestigious, relative to Northwestern. In the upward social comparison condition, the comparison was with the outcomes of students from Ivy League schools, which were characterized as superior to those of Northwestern students.

\footnotetext{
${ }^{5}$ The contrast weights for this test were $+3,-1,-1,-1$, for the lower SES stigma-relevant condition, higher SES stigma-relevant condition, lower SES stigma-irrelevant condition, and higher SES stigma-irrelevant condition, respectively.
} 


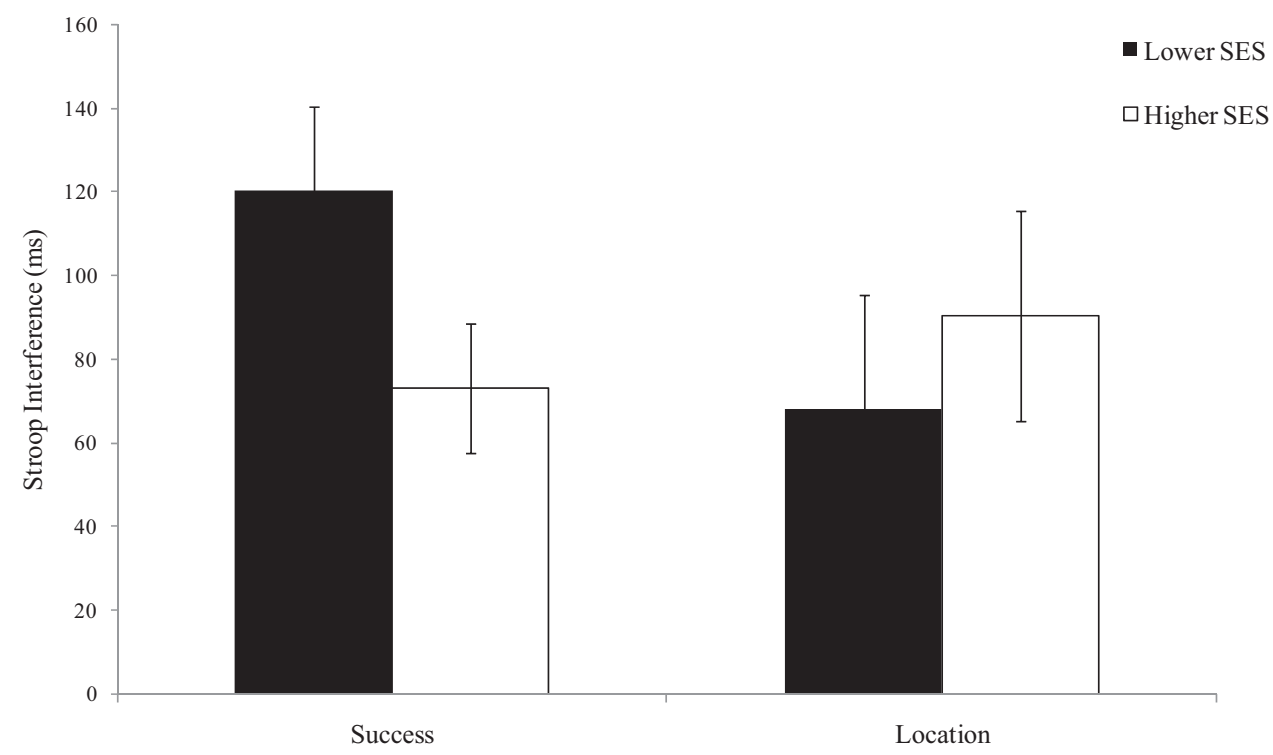

Figure 2. Study 3: Mean Stroop interference by participant socioeconomic status group and discussion topic.

This manipulation was expected to pose a threat to Northwestern students, regardless of SES background, and thus activate competency concerns for higher SES participants. In the downward social comparison condition, the comparison was with the outcomes of students at state schools, which were characterized as inferior to those of Northwestern students. Thus, this manipulation was expected to reduce the competency concerns of lower SES students.

As in Study 3, performance on the Stroop color-naming task served as the dependent measure of self-regulatory depletion. On the basis of the previous studies, we expected that in the control condition, because it activates academic competency concerns for lower but not higher SES participants, lower SES participants would evidence greater depletion compared with their higher SES peers. However, we expected this group difference to be eliminated by the social comparison manipulations. Specifically, the downward social comparison should attenuate lower SES participants' competency concerns, such that they are less depleted in this condition than in the control condition and thus no more depleted than their higher SES peers. This manipulation, therefore, should yield a pattern of results in the control and downward comparison conditions replicating that found in Study 3; specifically, lower SES participants in the control condition should be more depleted than either lower SES participants in the downward comparison condition or higher SES participants in either the control or downward comparison condition.

Furthermore, because we expected the upward social comparison condition to increase the demands of the self-presentation task, it should also eliminate the SES difference in depletion. That is, the upward social comparison should activate competency concerns for higher SES participants, and thus they should now also reveal depletion after self-presenting, similar to their lower SES counterparts. The upward social comparison manipulation (compared with control) should, therefore, yield a different pattern of results from that found in Study 3. Specifically, higher SES participants in the control condition should be the only group that does not suffer from depletion (again, excluding momentarily participants in the downward comparison condition). That is, higher SES participants in the control condition should perform better on the Stroop task (i.e., exhibit less Stroop interference) compared with higher SES participants in upward comparison condition and lower SES participants in either the control or upward comparison conditions.

\section{Method}

Participants and design. One hundred (67 female) Northwestern undergraduates participated in this study in exchange for partial fulfillment of a course requirement, or in exchange for $\$ 10$. Of these, $69 \%$ were White, $14 \%$ were Black, $9 \%$ were Latino, and $8 \%$ were biracial or multiracial. Participants were categorized as either higher $(n=49)$ or lower $(n=51)$ SES on the basis of household family income reported on a questionnaire at the beginning of the session. ${ }^{6}$ Again, individuals reporting incomes greater than $\$ 90,000$ were classified as higher SES, and those reporting incomes less than $\$ 90,000$ were classified as lower SES. Consistent with their categorization from the pretest, participants in the lower SES condition on average reported lower household incomes $(M=\$ 55,400)$ than those in the higher SES condition $(M=\$ 219,487), t(82)=6.21, p<.001, r=.57$. Study 4 employed a 2 (participant SES group: higher vs. lower) $\times 3$ (task demand manipulation: upward comparison vs. downward comparison vs. control) between-subjects design.

Procedure. Participants spent the first $10 \mathrm{~min}$ of the session completing questionnaires prior to the introduction of the selfpresentation task. Included in this packet of questionnaires was the

\footnotetext{
${ }^{6}$ Of the 51 participants classified as lower SES, 33 were White, seven were Latino, seven were Black, and four were biracial/multiracial. Of the 49 participants classified as higher SES, 37 were White, two were Latino, six were Black, and four were biracial/multiracial. In addition, White and racial minority participants were equally distributed across the three conditions.
} 
SES measure (an open-ended household income question). This study employed a self-presentation paradigm similar to Study 3 . As in Study 3, participants listened to an audio recording that explained the purpose of the study and instructions for the discussion task. All participants were assigned to the stigma-relevant condition and thus heard, "This research is especially important because a survey conducted by U.S. News and World Report indicates that ... which college you go to now has more influence in determining your success after graduation."

In the two experimental conditions, the comparison manipulation came next, in the form of an amplification of the study's purpose. Participants in the upward comparison condition heard: "In particular, this survey found that graduates of Ivy League universities, such as Harvard, Princeton, and Yale, consistently achieve greater levels of success compared to graduates of other non-Ivy-League private schools, such as Northwestern." In the downward comparison condition, participants heard the same description, but adjusted to make the downward comparison: "In particular, this survey found that graduates of elite private schools, such as Northwestern, consistently achieve greater levels of success compared to graduates of other public or state universities, such as the University of Illinois." Participants in the nocomparison control group were simply told: "In particular, this survey found that graduates of top schools like Northwestern tend to do well after graduation." Afterward, all participants were told that they had been assigned to discuss their expectations for their future outcomes.

Similar to Study 3, participants were told their completed recordings would be evaluated by a team of research assistants at the project headquarters, the location of which varied by condition. To emphasize the comparison manipulation, participants in the experimental conditions were told their tapes would be evaluated by research assistants at an exemplar of the comparison schools (i.e., an Ivy League or state school). Control condition participants were not given any information about who would be evaluating their tapes. Following the discussion task, participants completed the Stroop task described in Study 3. They completed three rather than two blocks of experimental trials; all other aspects of the tasks were identical. Finally, participants were debriefed about the purpose of the study, thanked, and dismissed.

\section{Results and Discussion}

Prior to analyses, the data from two participants were excluded: One participant's Stroop interference scores could not be calculated due to a high number of errors, and one participant's session suffered from a significant disruption. Thus, the final sample consisted of the remaining 98 participants. Stroop data were trimmed and transformed in the manner described in Study 3. Again, for ease of interpretation, values presented in the main text and figures are untransformed. Stroop interference scores ranged from $-92 \mathrm{~ms}$ to $397 \mathrm{~ms}(M=104 \mathrm{~ms}, S D=94 \mathrm{~ms})$.

We expected to find that, as with the stigma-irrelevant topic condition in Study 3, the downward comparison condition would reduce the demands of the task and thereby eliminate the SES group difference in depletion. Thus, we expected lower SES participants in the control condition to be significantly more depleted compared with either lower SES participants in the downward comparison condition or higher SES participants in either the control or downward comparison condition. Extending the results of Study 3, we also explored the potential effect of an upward social comparison on the depletion of higher SES participants after self-presentation. Because we expected the upward comparison condition to increase task demands, we predicted that higher SES participants would experience ego depletion in this condition, much like their lower SES peers in both the control and upward comparison conditions.

Stroop interference scores were first submitted to a two-way analysis of variance where participant SES group (higher, lower) and self-presentation task condition (upward comparison, downward comparison, control) were between-subjects factors. This analysis yielded a marginal interaction between SES group and condition, $F(2,92)=2.66, p=.076, \eta_{\mathrm{p}}{ }^{2}=.05$ (see Figure 3$)^{7}{ }^{7}$ Similar to our data-analytic approach in Study 3, we performed a series of planned contrasts to examine our a priori hypotheses. To test whether we replicated the pattern of results found in Study 3, we examined the means in the control and downward comparison conditions. Specifically, we employed a contrast to test the prediction that lower SES participants in the control condition (weighted +3 ) would be more depleted compared with participants in the other three groups (each weighted -1 ). Results of this analysis revealed that the predicted pattern was indeed reliable, $t(62)=3.21, p=.002, r=.38$. That is, replicating the findings of Study 3, lower SES participants in the control condition exhibited greater Stroop interference compared with lower SES participants in the downward comparison condition and higher SES participants in either the downward comparison or control condition.

Next, extending the findings of Study 3, we compared the impact of the upward comparison condition directly to the control condition. Here, because the upward comparison manipulation was expected to increase the demands of the self-presentation task, we expected this condition to result in an increase in the depletion experienced by the higher SES participants, relative to the control condition. In turn, we predicted that higher SES participants in the control condition would exhibit lower levels of depletion compared with participants in the remaining three groups: the lower SES participants in the control condition and both SES groups in the upward comparison condition. Indeed, the three versus one contrast ${ }^{8}$ testing this prediction was reliable, $t(60)=2.14, p=$ $.035, r=.27$.

Last, to explore further the effects of upward and downward comparisons on high SES and low SES participants, respectively, we directly compared the depletion (i.e., Stroop performance) of higher versus lower SES participants in each condition. Consistent with predictions, analyses revealed the predicted SES group difference in the no-comparison control condition, $t(30)=2.11, p=$ $.04, r=.36$. Replicating the patterns found in Studies 2 and 3, in other words, lower SES participants in the control condition evi-

\footnotetext{
${ }^{7}$ When race is included in this model, the interaction between SES group and condition remains virtually the same, $F(2,89)=2.52, p=.087$. Race does not significantly predict Stroop performance $(p>.44)$.

${ }^{8}$ The contrasts weights for this test were $-3,+1,+1,+1$, for higher SES control participants, higher SES upward comparison participants, lower SES upward comparison participants, and lower SES control participants, respectively.
} 


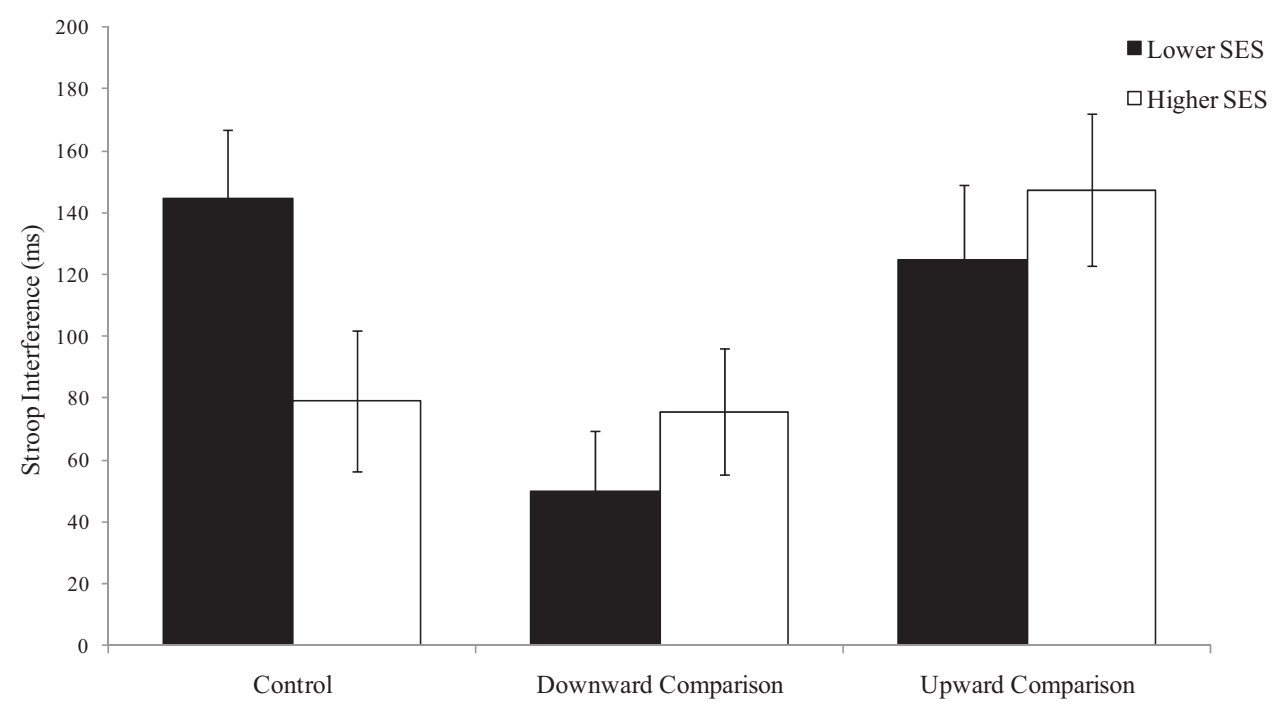

Figure 3. Study 4: Mean Stroop interference by participant socioeconomic status group and outgroup comparison condition.

denced greater Stroop interference than their higher SES counterparts in the control condition. Consistent with the results of the contrast analyses just described, the SES group difference was not reliable in either the upward comparison condition or the downward comparison condition $(t \mathrm{~s}<1, p \mathrm{~s}>.5) .{ }^{9}$ Taken together, the results of the present study suggest that the manipulation of upward and downward comparisons was able to level the playing field by increasing the academic competency concerns of, and thus the self-regulatory demands on, higher SES students and reducing the competency concerns of, and self-regulatory demands on, lower SES students, respectively.

The results of Study 4 are strikingly consistent with hypotheses. First, the findings from the control condition replicate the results of Studies 2 and 3 in which lower SES participants were more depleted than higher SES participants after engaging in a selfpresentation task related to academic achievement. Second, the present results provide compelling evidence that the SES group difference in depletion is likely a result of individuals' efforts to contend with their concerns about academic competency. Similar to Study 3, when the task demands were reduced for lower SES participants with the downward social comparison, they were no more depleted after the academic self-presentation task than their higher SES peers. The results of the upward social comparison condition in Study 4 offer additional support for the integral role of managing academic competency concerns in engendering the SES group differences in depletion found in Study 2. Indeed, when the task demands were equated by increasing them for the higher SES participants with an upward comparison, the SES group difference in depletion was once again eliminated. In turn, this study illustrates a critical point about the relationship between stigma and depletion: It is not simply belonging to a stigmatized group that is depleting but rather managing the concerns that arise from the stigmatizing situation.

The overall pattern of means, furthermore, suggests that the situation of the downward comparison is akin to the control condition for the higher SES participants, whereas the situation of an upward comparison is akin to the control condition for the lower SES participants. This evidence supports the proposal that, at baseline, discussing academic achievement may be more psychologically demanding for lower, compared with higher, SES students of elite private universities. The effectiveness of this manipulation suggests that for the lower SES participants, it may take an additional reminder-like an explicit downward comparison-to psychologically unburden them such that they experience engaging in self-presentation related to academic achievement in a manner similar to their higher SES counterparts. In other words, this finding supports the contention that it is the process of managing the concerns regarding competency that makes the experience of lower SES identity a depleting one.

\section{General Discussion}

Building on the stigma and social identity threat literatures, the present work examined the self-regulatory consequences of contending with a lower SES background in the setting of an elite university. The results of Study 1 brought empirical evidence to bear on Granfield's (1991) ethnographic work suggesting that possessing a lower SES social identity in an elite university environment can manifest in heightened concerns about the central

${ }^{9}$ The SES group difference was eliminated in the upward comparison condition primarily because the higher SES participants exhibited greater depletion in this condition than in the control condition, $t(29)=2.03, p=$ $.05, r=.35$. Lower SES participants, by contrast, exhibited comparable Stroop performance in the control and upward comparison conditions, $t(31)<1, p>.50$. As predicted, the SES group difference was eliminated in the downward comparison condition by shifting the balance of demands in the other direction. Specifically, the lower SES participants were less depleted in the downward comparison condition than they were in the control condition, $t(32)=3.34, p=.002, r=.51$. Higher SES participants, by contrast, exhibited similar levels of depletion in the control and downward comparison conditions, $t(30)<1, p>.90$. 
domain of that environment: namely, academic achievement. Indeed, the results of Study 1 revealed that lower SES students at an elite private university were both aware of and sensitive to their discrepancy along the dimension of SES and harbored greater concern regarding their academic competency than higher SES students at the university.

Studies 2-4 explored the self-regulatory consequences of harboring these identity-based concerns. Drawing on Inzlicht and colleagues' evidence of stereotype threat spillover (Inzlicht \& Kang, 2010) and conceptualization of stigma as ego depletion (Inzlicht et al., 2006), results supported the prediction that because they must manage their concerns about academic competency, lower SES students in an elite university context should be more depleted after engaging in self-presentation that is related to academic achievement. Using two different measures of ego depletion, results revealed that after talking about a topic related to academic achievement, lower SES students were more depleted compared with higher SES students (in Studies 2 and 3 and the control condition of Study 4).

Extending these findings, Study 4 revealed that the SES group difference in depletion could be eliminated by increasing or decreasing the task demands through a manipulation of individuals' academic competency concerns. Specifically, by either increasing higher SES students' academic competency concerns or decreasing such concerns for lower SES students, we were able to equate the extent to which higher and lower SES students were cognitively depleted after self-presenting in the academic domain. The fact that the SES group difference in depletion can be eliminated via relatively minor adjustments to the self-presentation task provides compelling evidence that rather than emerging from fundamental (i.e., fixed) differences in executive capacity between the groups, the differences in depletion found here are more likely to have arisen from differences in the psychological demands associated with self-presenting in the academic domain for lower versus higher SES students of elite private universities.

\section{Implications and Contributions}

The present findings have a number of theoretical and practical implications that we would like to highlight. First, this work contributes to our theoretical understanding of stigma and social identity threat. A particular strength of considering the social identity of SES in the context of an elite university is that it provides a relatively stringent, uncontaminated test of the notion proposed by Crocker et al. (1998) that stigma is the interaction between identity and context. That is, this work demonstrates that the burdens of stigma are truly the product of an identity in context and that the consequences of stigma itself (e.g., competency concerns) and coping with stigma (e.g., self-regulatory depletion) can occur even without a history of feeling devalued on the basis of that identity and in the absence of pervasive negative cultural stereotypes (see also Leyens, Desert, Croizet, \& Darcis, 2000). It is likely that most of these students who are lower in SES in the elite university context but actually in the U.S. middle class had not experienced academic competency concerns (stemming from SES) prior to coming to the university. Indeed, most of these students graduated at the top of their high school class. Nevertheless, the present data suggest that in this elite context-which relegates middle-class SES to deviant status-these students come to see themselves as different and devalued, and they become vulnerable to social identity threat. In other words, this work suggests that it is indeed possible to be both middle class and marginal.

In addition to building on theoretical work on stigma and social identity threat, the present findings support and extend Inzlicht et al.'s (2006) stigma as ego depletion hypothesis. Past work addressing this hypothesis has considered the effect for stigmatized identities that are visible-namely, Black students in an academic context and women in a math context. In contrast, the current work considers a stigma that is invisible-lower SES at an elite private university. Moreover, the previous work has primarily focused on the depleting effects of coping with stereotype threat (i.e., stereotype threat spillover; Inzlicht \& Kang, 2010). Our results, therefore, bolster Inzlicht et al.'s (2006) claims that coping with a stigmatized identity - even in the absence of stereotype threat-is ego depleting.

The present findings, furthermore, extend this previous research by examining the putative mechanism for stigma's depleting effects. We predicted that lower SES students in the elite university context would feel discrepant from their peers, which in turn would lead them to question their belonging in the context (Walton \& Cohen, 2007). Moreover, we posited that these broad belonging concerns would translate into concerns about competency in the dimension most central to the university context: namely, academic achievement. We propose that contending with such concerns-for instance, during a self-presentation task related to academic achievement—-drains lower SES students' self-regulatory resources and thus leaves them ego depleted. Consistent with this proposed mechanism, the results of Study 4 reveal that manipulating both higher and lower SES students' competency concerns exacerbated or attenuated the extent to which they experienced ego depletion after self-presenting in the academic domain. In other words, Study 4 provided compelling evidence that it is managing stigma-relevant concerns that is depleting, not simply being a member of a stigmatized group, engaging in a stigma-relevant (i.e., stereotype-relevant) task, or even being in a stigmatizing context (e.g., holding solo status).

Another contribution of this work is its attention to the influence of SES - a demographic characteristic that has received little attention from social psychologists (cf. Kraus \& Keltner, 2009; Kraus, Piff, \& Keltner, 2009). Furthermore, with its focus on the impact of relative - rather than objective-SES, the present work builds on the substantial literature linking relative SES to health outcomes. In particular, this literature underscores the importance of defining (and examining the consequences of) individuals' SES relative to others in their context (Adler, Epel, Castellazzo, \& Ickovics, 2000; S. Cohen et al., 2008; Singh-Manoux, Marmot, \& Adler, 2005; see also Sapolsky, 1993, 2004). Specifically, researchers have found that individuals' perceived social status relative to others (i.e., their social rank) predicts health outcomes (e.g., self-rated health, fat distribution, heart rate, cortisol habituation to repeated stressors) independent of-and sometimes more robustly than-objective measures of SES (Adler et al., 2000). This notion that the meaning, value, and consequences of one's identity will be defined, in part, by the social context is at the core of the social psychological literature on social stigma, suggesting that a social psychological lens may be particularly useful in 
shedding light on the ways in which SES influences individuals' experiences.

Several practical implications are also suggested by the present work. Most notably, the present findings shed additional light on the burden of stigma. Specifically, if stigma serves as a perpetual drain on individuals' self-regulatory resources, the strength model of self-control (Baumeister et al., 2007) suggests that lower SES students at elite universities will regularly have fewer resources available to contend with the challenges of college life. In other words, managing concerns about belonging and academic fit might result in fewer resources to devote to completing class assignments (Schmeichel, Vohs, \& Baumeister, 2003), successfully navigating interpersonal relationships (Finkel \& Campbell, 2001), and avoiding unhealthy behaviors (Muraven, Collins, \& Neinhaus, 2002). In short, the burden of stigma could leave its mark in multiple domains of life.

\section{Limitations and Future Directions}

One limitation of the current work is that SES is considered to the exclusion of other social identities. Social identities such as underrepresented racial minority status also have a profound impact on individuals' experiences in the elite private university context. Indeed, the current work builds on extant literature that has primarily focused on the experiences of racial minorities. It is important to note, therefore, that the results of each of the studies whose samples included racial minorities (Study 1, Study 2, and Study 4) do not change when analyses control for race. That said, the notion of intersectionality, which suggests that social identities can interact in various ways to influence individuals' outcomes (E. R. Cole, 2009), points to the need for future research to include samples that differ in both SES and race (among other social identities) to discern the distinct and potential interactive effects of these different forms of social stigma.

A second limitation of the present work is the relatively simple index of SES used. SES is best operationalized as a composite of multiple factors (i.e., parental education, occupation, and income), but for a number of practical reasons, the present study used family household income. Although it is likely that including multiple indicators renders a more complete (and accurate) gauge of an individual's SES background, the measure used herein nevertheless consistently yielded significant results. It is possible that the SES measure used in the present work has particular utility in the university context. For instance, it is possible that the availability of financial resources (or lack thereof) and financial aid eligibility (both based heavily on family household income) are the indicators most palpable to students in this context; individuals might be gauging their fit (i.e., their similarity to the prototypical student) on the basis of visual cues that mark financial means (e.g., computers, cell phones, cars, clothes). Thus, family income-to the extent that it determines the amount of disposable funds available to students to outfit themselves for college - may be a particularly meaningful aspect of SES in the current population. Future research should examine this possibility and the ways in which other indicators of SES, such as parental education, impact students' experiences in this context in ways that are similar to-and perhaps different from - the impact of family household income.

In addition to self-regulatory failure, extant evidence reveals other costs that arise from managing a stigmatized identity. In particular, the literature makes a particularly compelling case for the many costs that stem from concealing stigma - namely, negative consequences for both physical and mental health (S. W. Cole, Kemeny, Taylor, \& Visscher, 1996; S. W. Cole, Kemeny, Taylor, Visscher, \& Fahey, 1996; Major \& Gramzow, 1999; for a review see Pachankis, 2007). As the title of Granfield's (1991) ethnography ("Making It by Faking It") suggests, lower SES students who feel out of place in the elite academic environment may feel compelled to fake it-perhaps by adjusting how they dress, how they interact with others, and how they discuss their backgrounds - to conceal their SES identity and conform to the majority (i.e., their higher SES peers). Future research should systematically address the identity management strategies employed by lower SES students at elite universities and explore their affective, cognitive, and physiological consequences. Similarly, an important direction for future work may be identifying the coping strategies engaged by individuals who fare the best in this setting. Such endeavors will benefit the development of interventions designed to bolster lower SES students' feelings of belonging and legitimacy in these contexts.

\section{Conclusion}

In closing, it is worth noting that the current work, in considering the influence of social identities on individuals' outcomes in the domain of higher education, may have particular bearing on the notion of education as a social equalizer. Building on the legacy of the stereotype threat literature (Steele, 1997), this work provides further evidence suggesting that individuals' social identities may constrain their ability to perform to their potential in particular settings. Thus, although it is important to understand social disparities in gaining access to higher education, this work adds to the chorus of evidence suggesting that it is equally imperative to understand how the influence of social identities persists after individuals arrive in these environments.

\section{References}

Adler, N. E., Epel, E. S., Castellazzo, G., \& Ickovics, J. R. (2000) Relationship of subjective and objective social status with psychological and physiological functioning: Preliminary data in healthy White women. Health Psychology, 19, 586-592. doi:10.1037/02786133.19.6.586

Baron, R. M., \& Kenny, D. A. (1986). The moderator-mediator variable distinction in social psychological research: Conceptual, strategic, and statistical considerations. Journal of Personality and Social Psychology, 51, 1173-1182.

Baumeister, R. F., DeWall, C. N., Ciarocco, N. J., \& Twenge, J. M. (2005) Social exclusion impairs self-regulation. Journal of Personality and Social Psychology, 88, 589-604. doi:10.1037/0022-3514.88.4.589

Baumeister, R. F., Vohs, K. D., \& Tice, D. M. (2007). The strength model of self-control. Current Directions in Psychological Science, 16, $351-$ 355. doi:10.1111/j.1467-8721.2007.00534.x

Beilock, S. L., Ryell, R. J., \& McConnell, A.R. (2007). Stereotype threat and working memory: Mechanisms, alleviation, and spillover. Journal of Experimental Psychology: General, 136, 256-276.

Cohen, G. L., \& Garcia, J. (2008). Identity, belonging, and achievement. Psychological Science, 17, 365-369.

Cohen, S., Alper, C. M., Doyle, W. J., Adler, N., Treanor, J. J., \& Turner, R. B. (2008). Objective and subjective socioeconomic status and sus- 
ceptibility to the common cold. Health Psychology, 27, 268-274. doi: 10.1037/0278-6133.27.2.268

Cole, E. R. (2009). Intersectionality and research in psychology. American Psychologist, 64, 170-180. doi:10.1037/a0014564

Cole, S. W., Kemeny, M. E., Taylor, S. E., \& Visscher, B. R. (1996). Elevated physical health risk among gay men who conceal their homosexual identity. Health Psychology, 15, 243-251. doi:10.1037/02786133.15.4.243

Cole, S. W., Kemeny, M. E., Taylor, S. E., Visscher, B. R., \& Fahey, J. L. (1996). Accelerated course of human immunodeficiency virus infection in gay men who conceal their homosexual identity. Psychosomatic Medicine, 58, 219-231.

Crocker, J., Major, B., \& Steele, C. (1998). Social stigma. In S. Fiske, D. Gilbert, \& G. Lindzey (Eds.), Handbook of social psychology (Vol. 2, pp. 504-553). Boston, MA: McGraw-Hill.

Croizet, J., \& Claire, T. (1998). Extending the concept of stereotype threat to social class: The intellectual underperformance of students from low socioeconomic backgrounds. Personality and Social Psychology Bulletin, 24, 588-594. doi:10.1177/0146167298246003

DeWall, C. N., Baumeister, R. F., \& Vohs, K. D. (2008). Satiated with belongingness? Effects of acceptance, rejection, and task framing on self-regulatory performance. Journal of Personality and Social Psychology, 95, 1367-1382. doi:10.1037/a0012632

Evans, G. W., \& Schamberg, M. A. (2009). Childhood poverty, chronic stress, and adult working memory. Proceedings of the National Academy of Sciences, USA, 106, 6545-6549. doi:10.1073/pnas.0811910106

Farah, M. J., Shera, D. M., Savage, J. H., Betancourt, L., Giannetta, J. M., Brodsky, N. L., . . Hurt, H. (2006). Childhood poverty: Specific associations with neurocognitive development. Brain Research, 1110, 166174. doi:10.1016/j.brainres.2006.06.072

Finkel, E. J., \& Campbell, W. K. (2001). Self-control and accommodation in close relationships: An interdependence analysis. Journal of Personality and Social Psychology, 81, 263-277. doi:10.1037/00223514.81.2.263

Granfield, R. (1991). Making it by faking it: Working-class students in an elite academic environment. Journal of Contemporary Ethnography, 20, 331-351. doi:10.1177/089124191020003005

Gredler, M. E., \& Garavalia, L. S. (2000). Students' perceptions of their self-regulatory and other-directed study strategies: A factor analysis. Psychological Reports, 86, 102-108. doi:10.2466/PR0.86.1.102-108

Inzlicht, M., \& Ben-Zeev, T. (2000). A threatening intellectual environment: Why females are susceptible to experiencing problem-solving deficits in the presence of males. Psychological Science, 11, 365-371. doi:10.1111/1467-9280.00272

Inzlicht, M., \& Ben-Zeev, T. (2003). Do high-achieving female students underperform in private? The implications of threatening environments on intellectual processing. Journal of Educational Psychology, 95, 796805. doi:10.1037/0022-0663.95.4.796

Inzlicht, M., \& Kang, S. K. (2010). Stereotype threat spillover: How coping with threats to social identity affects aggression, eating, decisionmaking, and attention. Journal of Personality and Social Psychology, 99, 467-481. doi:10.1037/a0018951

Inzlicht, M., McKay, L., \& Aronson, J. (2006). Stigma as ego depletion: How being the target of prejudice affects self-control. Psychological Science, 17, 262-269. doi:10.1111/j.1467-9280.2006.01695.x

Kourlas, G. (2007, May 6). Where are all the black swans? The New York Times. Retrieved from http://www.nytimes.com

Kraus, M. W., \& Keltner, D. (2009). Signs of socioeconomic status: A thin-slicing approach. Psychological Science, 20, 99-106. doi:10.1111/ j.1467-9280.2008.02251.x

Kraus, M. W., Piff, P. K., \& Keltner, D. (2009). Social class, the sense of control, and social explanation. Journal of Personality and Social Psychology, 97, 992-1004. doi:10.1037/a0016357

Krieger, N., Williams, D. R., \& Moss, N. E. (1997). Measuring social class in U.S. public health research: Concepts, methodologies, and guidelines. Annual Review of Public Health, 18, 341-378. doi:10.1146/ annurev.publhealth.18.1.341

Leyens, J. P., Desert, M., Croizet, J. C., \& Darcis, C. (2000). Stereotype threat: Are lower status and history of stigmatization preconditions of stereotype threat? Personality and Social Psychology Bulletin, 26, 1189-1199. doi:10.1177/0146167200262002

Major, B., \& Gramzow, R. H. (1999). Abortion as stigma: Cognitive and emotional implications of concealment. Journal of Personality and Social Psychology, 77, 735-745. doi:10.1037/0022-3514.77.4.735

Major, B., \& O'Brien, L. (2005). The social psychology of stigma. Annual Review of Psychology, 56, 393-421.

Massey, D. S., Charles, C. Z., Lundy, G. F., \& Fischer, M. J. (2003). Source of the river: The social origins of freshmen at America's selective colleges and universities. Princeton, NJ: Princeton University Press.

Mendes, W. B., Blascovich, J., Major, B., \& Seery, M. (2001). Challenge and threat responses during downward and upward comparison. European Journal of Social Psychology, 31, 477-497. doi:10.1002/ejsp.80

Muraven, M., \& Baumeister, R. F. (2000). Self-regulation and depletion of limited resources: Does self-control resemble a muscle? Psychological Bulletin, 126, 247-259. doi:10.1037/0033-2909.126.2.247

Muraven, M., Collins, R. L., \& Neinhaus, K. (2002). Self-control and alcohol restraint: A test of the self-control strength model. Psychology of Addictive Behaviors, 16, 113-120. doi:10.1037/0893-164X.16.2.113

Muraven, M., Tice, D. M., \& Baumeister, R. F. (1998). Self-control as limited resource: Regulatory depletion patterns. Journal of Personality and Social Psychology, 74, 774-789. doi:10.1037/0022-3514.74.3.774

Murphy, M. C., \& Steele, C. M. (2009). The importance of context: Understanding the effects of situational cues on perceived identity contingencies and sense of belonging. Unpublished manuscript.

Murphy, M. C., Steele, C. M., \& Gross, J. J. (2007). Signaling threat: How situational cues affect women in math, science, and engineering settings. Psychological Science, 18, 879-885. doi:10.1111/j.1467-9280 .2007.01995.x

Noble, K. G., Norman, M. F., \& Farah, M. J. (2005). Neurocognitive correlates of socioeconomic status in kindergarten children. Developmental Science, 8, 74-87. doi:10.1111/j.1467-7687.2005.00394.x

Ostrove, J. M. (2003). Belonging and wanting: Meanings of social class background for women's constructions of their college experiences. Journal of Social Issues, 59, 771-784. doi:10.1046/j.00224537.2003.00089.x

Ostrove, J. M., \& Long, S. M. (2007). Social class and belonging: Implications for college adjustment. Review of Higher Education, 30, 363 389.

Pachankis, J. E. (2007). The psychological implications of concealing a stigma: A cognitive-affective-behavioral model. Psychological Bulletin, 133, 328-345. doi:10.1037/0033-2909.133.2.328

Purdie-Vaughns, V., Steele, C. M., Davies, P. G., Ditlmann, R., \& Crosby, J. R. (2008). Social identity contingencies: How diversity cues signal threat or safety for African Americans in mainstream institutions. Journal of Personality and Social Psychology, 94, 615-630. doi:10.1037/ 0022-3514.94.4.615

Richeson, J. A., \& Shelton, J. N. (2003). When prejudice does not pay: Effects of interracial contact on executive function. Psychological Science, 14, 287-290. doi:10.1111/1467-9280.03437

Richeson, J. A., \& Trawalter, S. (2005). Why do interracial interactions impair executive function? A resource depletion account. Journal of Personality and Social Psychology, 88, 934-947. doi:10.1037/00223514.88.6.934

Rimer, S., \& Finder, A. (2007, December 11). Harvard to aid students high in middle class. The New York Times. Retrieved from http:// www.nytimes.com

Sapolsky, R. M. (1993). Endocrinology alfresco: Psychoneuroendocrine 
studies of wild baboons. Recent Progress in Hormone Research, 48, 437-468.

Sapolsky, R. M. (2004). Why zebras don't get ulcers. New York, NY: Holt.

Schmeichel, B. J., Vohs, K. D., \& Baumeister, R. F. (2003). Intellectual performance and ego depletion: Role of the self in logical reasoning and other information processing. Journal of Personality and Social Psychology, 85, 33-46. doi:10.1037/0022-3514.85.1.33

Sekaquaptewa, D., \& Thompson, M. (2003). Solo status, stereotypes, and performance expectancies: Their effects on women's public performance. Journal of Experimental Social Psychology, 39, 68-74.

Singh-Manoux, A., Marmot, M. G., \& Adler, N. E. (2005). Does subjective social status predict health and change in health status better than objective status? Psychosomatic Medicine, 67, 855-861. doi:10.1097/ 01.psy.0000188434.52941.a0

Spencer, B., \& Castano, E. (2007). Social class is dead. Long live social class! Stereotype threat among low socioeconomic status individuals. Social Justice Research, 20, 418-432. doi:10.1007/s11211-0070047-7

Steele, C. M. (1997). A threat in the air: How stereotypes shape intellectual identity and performance. American Psychologist, 52, 613-629. doi: 10.1037/0003-066X.52.6.613

Steele, C. M., \& Aronson, J. (1995). Stereotype threat and the intellectual test performance of African Americans. Journal of Personality and Social Psychology, 69, 797-811. doi:10.1037/0022-3514.69.5.797

Steele, C. M., Spencer, S. J., \& Aronson, J. (2002). Contending with group image: The psychology of stereotype and social identity threat. In M. P. Zanna (Ed.), Advances in experimental social psychology (Vol. 34, pp. 379-440). San Diego, CA: Academic.

Stroop, J. R. (1935). Studies of interference in serial verbal reactions. Journal of Experimental Psychology, 18, 643-662. doi:10.1037/ h0054651

Walton, G. M., \& Cohen, G. L. (2007). A question of belonging: Race, social fit, and achievement. Journal of Personality and Social Psychology, 92, 82-96. doi:10.1037/0022-3514.92.1.82

Received August 31, 2009

Revision received October 12, 2010

Accepted October 15, 2010

\section{Showcase your work in APA's newest database.} PsycTESTS

Make your tests available to other researchers and students; get wider recognition for your work.

"PSycTESTS is going to be an outstanding resource for psychology," said Ronald F. Levant, PhD. "I was among the first to provide some of my tests and was happy to do so. They will be available for others to use-and will relieve me of the administrative tasks of providing them to individuals."

Visit http://www.apa.org/pubs/databases/psyctests/call-for-tests.aspx to learn more about PsycTESTS and how you can participate.

Questions? Call 1-800-374-2722 or write to tests@apa.org. Not since PsycARTICLES has a database been so eagerly anticipated! 